\title{
Koniec narracji triumfalistycznej w fan studies
}

\section{The end of fan studies' triumphalist narrative}

\author{
Mel Stanfill, Exploiting Fandom: How the Media Industry Seeks \\ to Manipulate Fans, University of Iowa Press, Iowa 2019.
}

DOI: 10.12775/LL.2.2021.010 | CC BY-ND 3.0 PL

Exploiting Fandom opublikowane zostało przez wydawnictwo znajdujące się przy University of Iowa, największym światowym ośrodku badań z dziedziny fan studies. Książka ta, słusznie, stała się jednym z najgłośniejszych w tej dyscyplinie opracowań ostatnich lat. Mel Stanfill udało się na niecałych trzystu stronach dokonać wnikliwej i podpartej szczegółową znajomością teorii analizy interakcji rynku z fanami. Autorka, co bardzo nietypowe, skupia się nie tyle na samej aktywności fanowskiej, zazwyczaj znajdującej się w centrum rozważań fantropologów, co raczej na działaniach koncernów medialnych i korporacji skonfrontowanych z odbiorem swoich produkcji. W jednakowym stopniu uwzględnia przy tym zarówno fanów fantastyki czy komiksu, jak i kibiców, dostrzegając liczne podobieństwa w sposobach traktowania i dyscyplinowania jednych i drugich przez przemysł rozrywkowy. Opracowanie bazuje na pogłębionych wywiadach przeprowadzonych z pracownikami korporacji medialnych, analizie regulaminów znajdujących się na stronach największych franczyz oraz na namyśle nad sposobami reprezentacji fanów w tekstach kultury oficjalnej. 
Stanfill przyjmuje szeroką perspektywę biopolityczną, wychodząc z założenia, że analizowane procesy „nie mogą być zrozumiałe dzięki badaniu fanów jako jednostek lub poszczególnych kultur, bo przemysł nie na takiej zasadzie wchodzi z nimi w interakcje” (s. 10).

Jeśli rok 1992 uznawać za moment narodzenia się fan studies (to wówczas ukazały się Textual Poachers Henry’ego Jenkinsa, Enterprising Women Camille Bacon-Smith i antologia Lisy Lewis The Adoring Audience, zawierająca głośny tekst Johna Fiske'a The Cultural Economy of Fandom), to rok 2019 należałoby potraktować jako moment zmiany paradygmatu. Choć przedtem pojawiały się głosy sceptyczne wobec optymizmu wspomnianych wyżej pierwszych opracowań i późniejszej Kultury konwergencji (Jenkins, 2006), dopiero po blisko trzech dekadach doczekaliśmy się obszernych, systematycznych opracowań ukazujących opisywane przez Jenkinsa zmiany w przemyśle rozrywkowym w świetle negatywnym. Chodzi mianowicie o książkę Fake Geek Girls Suzanne Scott oraz właśnie Exploiting Fandom. Podczas gdy większość opracowań skupia się na twórczości fanowskiej ukazywanej jako forma subwersji, a pozycje poświęcone interakcjom fanów z przemysłem rozrywkowym utrzymane są w tonie optymistycznym, Stanfill uderza momentami w tony niemal katastroficzne. Odcina się jednoznacznie od ustanowionej przez Jenkinsa i dominującej w fan studies „narracji triumfalistycznej”, którą streszcza następująco: „fani [...] są nowymi odbiorcami idealnymi. Po długich cierpieniach wynikających z niezasłużonej stygmatyzacji przechodzą do głównego nurtu i od teraz już wszystko jest cacy” (s. 21). Nie oznacza to, że autorka nie dostrzega interakcji fanów z przemysłem lub że nie bierze pod uwage wpływu, jaki na media wywiera ich obecność, bowiem to do nich zaczyna być adresowanych coraz więcej treści medialnych. Wyłożona w Kulturze konwergencji wizja przyszłości była niemal utopijna: widzowie i czytelnicy, za sprawą rozwoju opowieści transmedialnych coraz bardziej zaangażowani i coraz bardziej podobni fanom, mieli oddalać się od wzorca biernego odbioru, zaś producenci mieli z fanami współpracować. Stanfill nie neguje zmian, które nastąpiły - zadaje jednak kluczowe pytania: O których fanów chodzi? Kto dyktuje zasady tej współpracy?

Tematem książki nie są faktycznie istniejący i działający fani, ale fani jako konstrukt dyskursywny i sposób, w jaki ten konstrukt powstaje. Stanfill zastanawia się zatem nad tym, jakie osoby ukazuje się zazwyczaj jako fanów i - pośrednio - które z nich traktowane są jako idealni przedstawiciele tej grupy. Zwraca uwage nie tylko na marginalizacje kobiet, osób niebiałych i innych mniejszości, ale dostrzega także kształt narracji dotyczących białych mężczyzn. Stereotyp nerda - niewysportowanego, nielubianego i sfrustrowanego seksualnie chłopaka poświęcającego cały czas wolny niszowym i eskapistycznym rozrywkom - przez dekady służył wyśmiewaniu mężczyzn, którzy nie odnieśli sukcesów towarzyskich i zawodowych. Stanfill zwraca uwagę na to, że w XXI w. coraz bardziej popularne stały się jednak narracje o odkupieniu (redemption) nerda, który dzięki swojej wiedzy i racjonalizmowi może awansować społecznie i spełnić się w typowo męskich rolach. Choć ich punktem wyjścia pozornie jest 
sytuacja marginalizacji, $\mathrm{w}$ ostatecznym rozrachunku służą one reafirmacji tradycyjnych ról płciowych i wzmocnieniu hegemonii. Przede wszystkim zaś samo przywoływanie owego stereotypu prowadzi do wyparcia z przestrzeni publicznej osób odbiegających od niego pod względem rasy, płci czy orientacji seksualnej.

W centrum swoich rozważań Stanfill ustawia zatem ideę normatywności i sposoby jej konstruowania przez przemysł rozrywkowy. Sytuacja opisywanego w Kulturze konwergencji fana rzeczywiście uległa poprawie, a miejsce stygmatyzacji zajęły próby zaspokojenia jego potrzeb. Stało się tak jednak przede wszystkim dlatego, że to on jest projektowany jako idealny konsument. Proces tworzenia modelowego fana przez przemysł rozrywkowy, przejawiający się w tym, kto jest adresatem komunikatów i jak jest on pokazywany oraz z myślą o kim i o jakich działaniach tworzone są strony internetowe, nierozłącznie wiąże fanostwo z konsumpcją. Twórczość transformująca czy fanowski aktywizm, ponieważ nie przynoszą zysku przemysłowi, traktowane są jako nienormatywne i często nie przewiduje się ich w afordancjach oficjalnych stron i forów. Praktyki te nie są wprost zakazywane i wciąż mogą istnieć, jednak albo spychane są do osobnych przestrzeni, bowiem oficjalne strony uniemożliwiają publikację określonych treści, albo traktowane są jako aberracja. Zdaniem Stanfill przykładem takiego podejścia jest szereg kontrowersji, które znalazły kulminację latem 2016 r., kiedy to pod wpływem oburzenia części fandomu wywołanego uśmierceniem nieheteronormatywnej postaci z serialu The $100 \mathrm{w}$ mediach wybuchła panika moralna. Fanów należących do różnych grup, zainteresowanych odmiennymi tekstami, podejmujących bardzo niejednorodne działania i reprezentujących skrajnie różne poglądy polityczne, skategoryzowano zbiorczo jako roszczeniowych, tworząc ich obraz jako homogenicznej grupy dążącej do przejęcia władzy nad przemysłem rozrywkowym i terroryzującej twórców. Ten przypadek paniki moralnej autorka traktuje jako próbe pacyfikacji grupy (która i tak nie jest uprzywilejowana), podkreślając zarazem, jak niewiele wspólnego z rzeczywistością ma - utrwalone wszak również przez fantropologów - przekonanie o sprawczości fandomu. Exploiting Fandom jest przede wszystkim książką o niesymetryczności relacji między fanami a przemysłem, który sprawuje nad nimi kontrole.

Nadrzędną metaforą organizującą zawarte w książce rozważania jest obraz pasterza zapewniającego zwierzętom pożywienie i ochrone przed niebezpieczeństwami oraz trzody, dzięki której pasterz się utrzymuje. $Z$ jednej strony zatem koncerny medialne i sportowe kultywują swój wizerunek jako dobrotliwych opiekunów, którzy dostarczają fanom kolejnych tekstów kultury i nie przeszkadzają im w amatorskiej twórczości. $Z$ drugiej natomiast strony korporacje te korzystają z władzy pastoralnej w zakresie, który nigdy dotąd nie był możliwy. Stanfill sięga po rozpoznania Foucaulta, rozpatrując koncerny medialne i właścicieli praw autorskich jako instytucje biowładzy, sprawujące kontrolę nad populacją fanów, jej decyzjami i migracjami. Jak dowodzi, kluczowym procesem umożliwionym przez kulturę konwergencji stało się udomowienie fanów. Już we wstępie wskazuje: 
Tak jak trzoda jest hodowana w ten sposób, by być jak największa i jak najłagodniejsza, [tak samo] zaproszenia wystosowane przez przemysł rozrywkowy do fanów mają za zadanie uczynić ich bardziej użytecznymi i podatnymi na kontrolę, przekształcając ich w zasób, który można wykorzystać (s. 11).

Sprawowanie tego typu niewidzialnej władzy jest możliwe przede wszystkim dzięki upowszechnieniu się internetu, które Jenkins traktował niemal jako gwarancję demokratyzacji. Stanfill podkreśla znaczenie problemu, który nie jest nowy, ale wciąż wydaje się rzadko eksponowany w obrębie fantropologii. Chodzi mianowicie o sposób, w jaki technologie Web 2.o umożliwiają pozyskiwanie i systematyzację szczegółowych danych o upodobaniach publiczności, które wcześniej dostępne były tylko w szczątkowym stopniu za pośrednictwem statystyk sprzedaży czy wskaźników Nielsena. Jak podkreśla autorka, pozorna demokratyzacja internetu pozwoliła osobom dysponującym kapitałem wzbogacić się jeszcze bardziej, wcale nie poprawiając statusu majątkowego tych, którzy znajdują się niżej w kapitalistycznej hierarchii. Wraz z przekształceniem użytkowników internetu w twórców zamieszczanych tam treści, odbiorcy sami zaczęli dostarczać koncernom medialnym informacji o sobie i swoich oczekiwaniach wobec produktu, wykonując nieodpłatnie pracę, która umożliwia poprawienie wyników sprzedaży.

Część Exploiting Fandom poświęcona szeroko pojętej pracy wykonywanej przez fanów wydaje się szczególnie interesująca. Stanfill analizuje bowiem wątek zadziwiająco rzadko poruszany w fan studies: kwestię nieodpłatnej pracy i tego, kto ma prawo do jej owoców. Druga połowa książki dotyczy statusu prawnego twórczości fanowskiej i szokująco niesymetrycznej relacji pomiędzy właścicielami praw autorskich i fanami. Owa niesymetryczność ujawnia się niekiedy dopiero po przeczytaniu tekstu pisanego drobnym drukiem w regulaminach oficjalnych serwisów internetowych czy forów. Stanfill szczegółowo pokazuje nadużycia ze strony przemysłu, który nie tylko działa niekiedy wbrew interesom publicznym, ale uzurpuje sobie prawa, których w rzeczywistości nie ma, lub wytwarza dodatkowe zapisy, z których istnienia odbiorcy produktów nie zdają sobie sprawy. Przede wszystkim użytkownicy internetu i innych mediów nie są informowani wprost o zyskach, które będą czerpane z ich działań, więc nie mają możliwości wyrazić świadomej zgody na uczestnictwo w przemyśle. Dzięki podejściu biopolitycznemu autorka omawianej publikacji jest w stanie w przekonujący sposób opisać fanów i ich najbardziej osobiste upodobania jako towar, który staje się przedmiotem handlu. Ukazuje jednocześnie, jak duża część operacji zyskownych dla koncernów reklamowych, właścicieli platform lub franczyz wykonywana jest przez nieświadomych tego użytkowników, dostarczających narzędzi do kontroli samych siebie.

Zastanawiając się nad pracą twórczą fanów i - w szczególności - fanek, Stanfill odwołuje się do idei lovebor, czyli nieodpłatnej pracy wykonywanej z miłości, pogłębiając obserwacje dokonane wcześniej przez Kristinę Busse 
(2015). Exploiting Fandom pokazuje, że fantazmat ekonomii daru i odrzucenie przez część fandomu kapitalizmu stwarzają idealne warunki do wykorzystywania pracy jego członków. Fanowska produkcja, pozornie istniejąca na zewnątrz struktur rynkowych, jest do nich z łatwością wcielana - jako źródło przychodów reklamodawców, jako darmowa reklama franczyzy czy jako zasób łatwo dostępnych informacji o gustach i oczekiwaniach widowni. Biorąc pod uwagę, że z twórcami fanowskimi nie zawiera się żadnych umów i nie informuje się ich o przychodach, które mogą oni generować dla właścicieli praw autorskich, wykorzystywanie ich aktywności przez przemysł rozrywkowy trudno postrzegać inaczej niż w kategoriach wyzysku.

Jeśli czegoś w Exploiting Fandom miałoby brakować, to byłaby to, jak sądzę, kwestia sprawczości fanów. Stanfill odmalowuje przekonującą wizję sprzężenia, w ramach którego przemysł pozornie odpowiada na pragnienia i oczekiwania fandomu, sam je najpierw wywołując. Nie rozwija jednak wątku zaspokojenia fanowskiego pożądania, skupiając się na jego kształtowaniu. Same zmiany wprowadzane w tekstach kultury pod wpływem wiedzy o fanowskich upodobaniach stanowią temat, który wymagałby osobnej analizy, jest więc rzeczą zrozumiałą, że akurat ta kwestia została zmarginalizowana, by dało się wyeksponować mechanizmy biowładzy.

Książka Stanfill stanowi fascynującą lekture nie tylko dlatego, że opracowanie poparte zostało wnikliwymi i doskonałymi metodologicznie badaniami, a materiał jest świetnie uporządkowany retorycznie. Exploiting Fandom to przede wszystkim Kultura konwergencji Jenkinsa à rebours - opracowanie poświęcone dokładnie tym samym procesom, ale skonstruowane nie w oparciu o myślenie życzeniowe, ale o zadawanie niewygodnych pytań. Popularyzacja internetu, umożliwienie milionom odbiorców wyrażania swoich opinii i tworzenia sieci znajomości, zwrócenie przez przemysł rozrywkowy uwagi na najaktywniejszych członków widowni czy rozkwit łatwo dostępnej i powstającej na niespotykaną dotąd skalę twórczości fanowskiej stanowią fakty. Nie sprawia to jednak, że optymistyczne prognozy Jenkinsa dotyczące rosnącego upodmiotowienia fanów i emancypacji dotąd zmarginalizowanych grup stają się prawdziwe. Jak pisze Stanfill,

[p]rzemysł nie pyta fanów, czy chcą zostać udomowieni. [...] Zmalała (choć nie zniknęła) stygmatyzacja fanów, zwiększył się dostęp do informacji, a struktury prawne zostały poluzowane. $\mathrm{Z}$ braku przyzwyczajenia do myślenia w kategoriach systemowych, ale też z powodu celowych działań [przemysłu], trudno nam [jednak] dostrzec cenę, którą za to płacimy: normalizację $\mathrm{w}$ ramach wąskiej i dla wielu wykluczającej wersji fandomu, wykonywanie nieodpłatnej pracy i porzucenie krytycznych tradycji fanostwa (s. 197).

Stanfill nie rozstrzyga, czy dojdzie w końcu do całkowitego udomowienia fanów. Zostawia te decyzję fandomowi - postulując tylko, by była ona podjęta świadomie i na własnych zasadach. 


\section{BIBLIOGRAFIA}

Bacon-Smith, C. (1992). Enterprising women: Television fandom and the creation of popular myth. Philadelphia: University of Pennsylvania Press.

Busse, K. (2015). Fan Labor and Feminism: Capitalizing on the Fannish Labor of Love. Cinema Journal, 54(3), 110-115. doi:10.1353/cj.2015.0034

Jenkins, H. (1992). Textual Poachers: Television Fans \& Participatory Culture. Studies in culture and communication. New York: Routledge.

Jenkins, H. (2006). Convergence Culture: Where Old and New Media Collide. New York: New York University Press.

Lewis, L. A. (ed.) (1992). The adoring audience: Fan culture and popular media. London: Routledge.

Scott, S. (2019). Fake geek girls: Fandom, Gender, and the Convergence Culture Industry. New York: New York University Press. 